\title{
PRODUTIVIDADE DE PASTOS CONSORCIADOS COM LEGUMINOSAS FORRAGEIRAS
}

Clair Jorge Olivo ${ }^{1}$, Carlos Alberto Agnolin ${ }^{1}$, Vinícius Felipe Bratz ${ }^{1}$, Michelle Schalemberg Diehl ${ }^{1}$, Gabriela Descovi Simonetti ${ }^{1}$, Marcos da Rosa Correa ${ }^{1}$, Patrícia Fernandes Rodrigues ${ }^{1}$, Dreisse Gabbi Fantineli ${ }^{1}$, Jéssica Soares Nunes ${ }^{1}$, Cláudia Marques de Bem ${ }^{1}$

${ }^{1}$ Universidade Federal de Santa Maria - E-mail: clairo@ smail.ufsm.br

\section{RESUMO}

O objetivo desta pesquisa foi avaliar a massa da forragem e a taxa de lotação em três sistemas forrageiros com capim elefante $(\mathrm{CE})$ + azevém $(\mathrm{AZ})$ + espécies de crescimento espontâneo (ECE); $\mathrm{CE}+\mathrm{AZ}+\mathrm{ECE}+$ amendoim forrageiro $(\mathrm{AM})$; e $\mathrm{CE}+\mathrm{AZ}+\mathrm{ECE}+$ trevo vermelho (TV) durante os períodos hibernal e estival, em lotação rotacionada com bovinos leiteiros. Os valores médios de produção de forragem e da taxa de lotação foram de 9,19; 9,59; 9,78 $\mathrm{Mg} \mathrm{ha}^{-1}$ e de 2,20; 2,47 e 2,30 $\mathrm{UA} \mathrm{ha}^{-1} \mathrm{dia}^{-1}$ para os respectivos sistemas forrageiros. Melhores resultados foram obtidos nos consórcios com amendoim forrageiro e com trevo vermelho.

Palavras-chave: Arachis pintoi, Bovinos leiteiros, Lolium multiflorum, Pennisetum purpureum, Trifolium pratense

\section{PRODUCTIVITY OF PASTURES INTERCROPPED WITH FORAGE LEGUMES}

\section{ABSTRACT}

The objective of this research was to evaluate the forage mass and stocking rate of three grazing systems with Elephant grass $(\mathrm{EG})+$ Italian ryegrass (IR) + spontaneous growing species $(\mathrm{SGS}) ; \mathrm{EG}+\mathrm{IR}+\mathrm{SGS}+$ Forage peanut; and EG + IR + SGS + Red clover, for cool and warmseason in rotational grazing with dairy cattle. The average of forage production and stocking rate were 9.19, 9.59, 9.78 Mg ha and 2.20, 2.47 and 2.30 $\mathrm{UA} \mathrm{ha}^{-1} \mathrm{dia}^{-1}$ for the respective grazing systems. Better results were found on mixed pastures with Forage peanut and Red clover.

Keywords: Arachis pintoi, Dairy cattle, Lolium multiflorum, Pennisetum purpureum, Trifolium pretense 


\section{INTRODUÇÃO}

A produção de leite é uma das atividades mais importantes, notadamente na agricultura familiar. As pastagens, na maioria das propriedades, são a base da alimentação dos animais, constituídas especialmente por gramíneas estabelecidas em monocultivo. Nesse contexto, espécies forrageiras perenes, como o capim elefante, merecem destaque, especialmente por sua elevada capacidade de produção de forragem. Na região Sul do Brasil sua produção é estacional, o que implica em um vazio forrageiro no período hibernal. Nessa condição, normalmente, os agricultores utilizam níveis elevados de adubação, especialmente a nitrogenada.

Para sistemas forrageiros sustentáveis, com uso da mesma área no ano todo, é recomendada a mistura de espécies forrageiras de ciclo estival com espécies de ciclo hibernal, que proporciona um ambiente pastoril favorável e a extensão do período de utilização dos pastos (AZEVEDO JUNIOR et al., 2012). A consorciação de plantas forrageiras equilibra a produção de forragem e o seu valor nutritivo (LENZI et al., 2009; SOBCZAK et al., 2005) e reduz gastos com adubação nitrogenada, devido à contribuição dessas plantas pelo processo de fixação biológica do nitrogênio (SANTOS et al., 2002; THOMAS, 1992).

As dificuldades do consórcio estão associadas às diferenças entre gramíneas e leguminosas, sendo que estas se estabelecem de forma mais lenta, além das dificuldades de manejo (CASTILHO, 2001), condições estas, que podem comprometer a persistência delas na pastagem. Apesar do potencial das leguminosas forrageiras, poucos agricultores fazem uso em suas pastagens. Também são escassos estudos, principalmente que envolvem bovinos leiteiros sob condições de pastejo.

Dentre as leguminosas com potencial de uso em sistemas forrageiros, destacam-se o amendoim forrageiro, devido a sua elevada capacidade de rebrote, de produção e valor nutritivo da forragem (BRESOLIN et al., 2008). Outra leguminosa importante para a região Sul é o trevo vermelho, que pode ser utilizada em consórcio com gramíneas de ciclo hibernal e proporciona maior período de utilização da pastagem, bom rendimento e qualidade de forragem (PAIM \& RIBOLDI, 1994).

A hipótese da pesquisa é de que a introdução das leguminosas nos respectivos sistemas forrageiros contribui para elevar a produção de forragem e a taxa de lotação. $\mathrm{O}$ objetivo foi avaliar a produtividade de três 
sistemas forrageiros constituídos por capim elefante, azevém anual, espécies de crescimento espontâneo e amendoim forrageiro ou trevo vermelho.

\section{MATERIAL E MÉTODOS}

Todas as técnicas e os procedimentos utilizados na presente pesquisa foram aprovados pelo Comitê de Ética em Experimentação Animal da Universidade Federal de Santa Maria (sob o protocolo $n^{\text {o }}$ 23081016073/2011-27, parecer 113/2011). O trabalho foi conduzido em área experimental do Departamento de Zootecnia da UFSM, situado na região da Depressão Central, com altitude de $95 \mathrm{~m}$ acima do nível do mar, latitude $29^{\circ} 43^{\prime}$ Sul e longitude $53^{\circ}$ 42' Oeste, em solo classificado como Argissolo Vermelho eutrófico (EMBRAPA, 2006), no período de 27 de maio de 2011 a 04 de maio de 2012.

O clima da região é o subtropical úmido (Cfa) segundo a classificação de Köppen. Os valores de temperatura média, precipitação pluvial, insolação e umidade relativa do ar do período experimental foram de $19^{\circ} \mathrm{C}, 114 \mathrm{~mm} / \mathrm{mês}, 205$ h e $76 \%$ (Figura 1). Destaca-se que nos meses de setembro e novembro de 2011 e janeiro de 2012 a precipitação ficou abaixo do esperado, sendo 61,$2 ; 41,6$ e 68,8 mm/mês, no entanto, houve um acréscimo de horas de insolação de 25 , 15 e 22\%, respectivamente, quando comparada às normais climatológicas dos últimos trinta anos.

Os tratamentos foram constituídos por três sistemas forrageiros: a) mistura base constituída por capim elefante, azevém e espécies de crescimento espontâneo; b) mistura base e introdução de amendoim forrageiro; c) mistura base e introdução de trevo vermelho.

A área experimental utilizada foi de 0,78 ha (subdividida em seis piquetes de 0,13 ha cada) com capim elefante (Pennisetum purpureum Schum.), cv. Merckeron Pinda, já estabelecido desde 2004, em linhas afastadas a cada $4 \mathrm{~m}$. Para os sistemas consorciados, as leguminosas foram estabelecidas nas entrelinhas, onde em dois piquetes preservou-se o amendoim forrageiro (Arachis pintoi Krapovickas \& Gregory) cv. Amarillo, estabelecido em 2006, e em outros dois, em 10 de maio de 2011, fez-se a semeadura do trevo vermelho (Trifolium pratenseL.) cv. Estanzuela 116, à razão de $11 \mathrm{~kg} \mathrm{ha}^{-1}$. A seguir, foi semeado o azevém (Lolium multiflorum Lam.), cv. Comum, mediante escarificação do solo, em toda área experimental, à razão de $40 \quad \mathrm{~kg}$ ha $^{-1}$. 


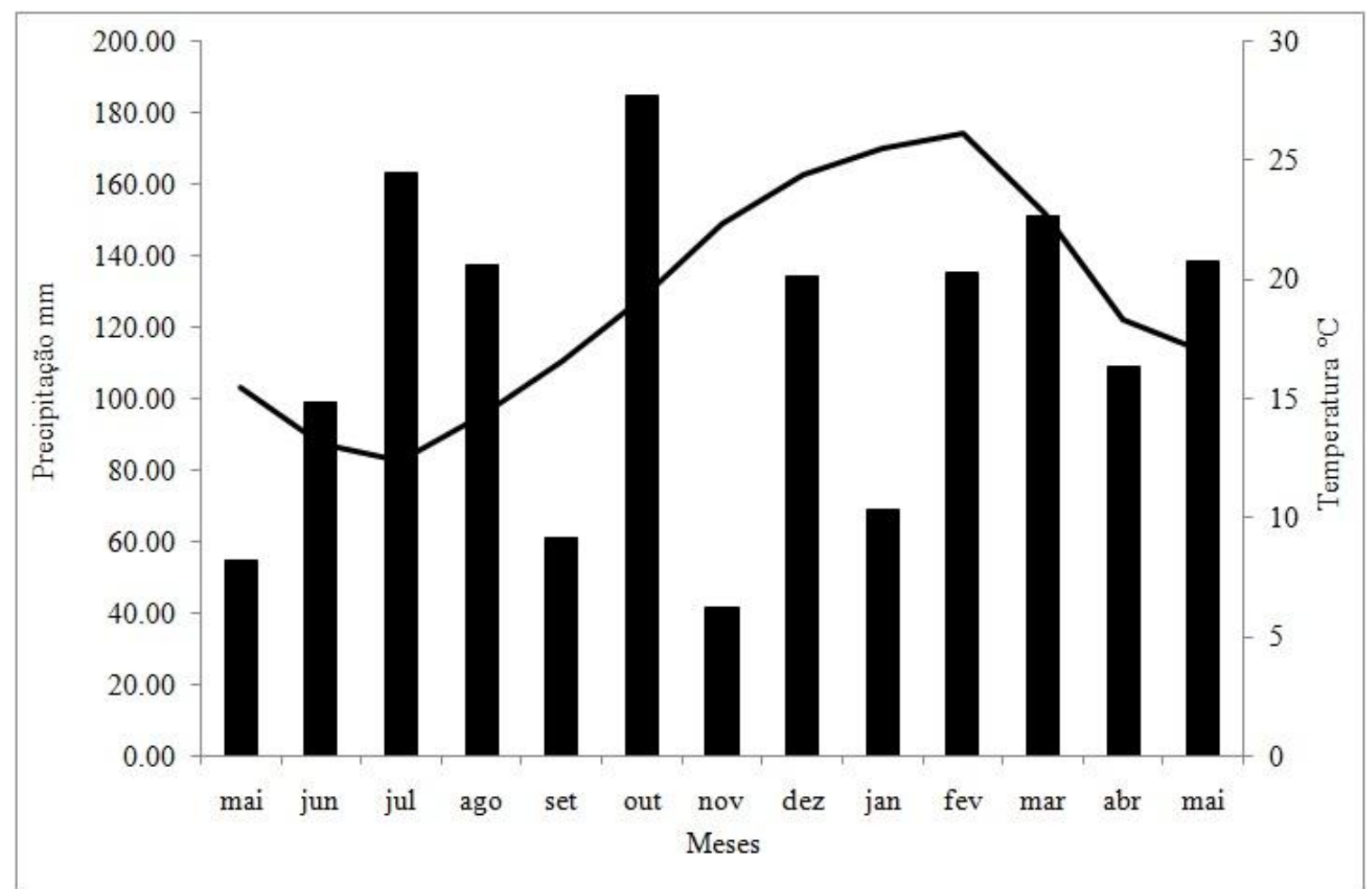

Figura 1. Precipitação pluvial mensal $(\mathrm{mm})$ e temperatura do ar média mensal $\left({ }^{\circ} \mathrm{C}\right)$, no período de maio de 2011 a maio de 2012 na região de Santa Maria, RS.

Os resultados da análise de solo foram: Índice SMP 5,7; P 14,5 $\mathrm{mg} \mathrm{dm}^{-3}$; $\mathrm{K}$ $0,13 \mathrm{cmol}_{\mathrm{c}} \mathrm{dm}^{-3} ; \mathrm{Al}^{3+} 0,9$ cmol $_{c} \mathrm{dm}^{-3} ; \mathrm{Ca}^{2+}$ $5,5 \mathrm{cmol}_{\mathrm{c}} \mathrm{dm}^{-3} ; \mathrm{Mg}^{2+} 2,3 \mathrm{cmol}_{\mathrm{c}} \mathrm{dm}^{-3} ; \mathrm{MO}$ $3,0 \%$; saturação de bases $54,0 \%$ e saturação por alumínio $12,2 \%$.

Para a adubação de base foram utilizados $200 \mathrm{~kg} / \mathrm{ha}$ de $\mathrm{N}-\mathrm{P}_{2} \mathrm{O}_{5}-\mathrm{K}_{2} \mathrm{O}(5-20-$ 20), divididos em duas aplicações, a primeira no estabelecimento do azevém e a segunda aplicação em outubro de 2011. Como adubação de cobertura, utilizou-se $45 \mathrm{~kg} \mathrm{ha}^{-1}$ de $\mathrm{N}$ sob a forma de uréia, parcelada em quatro aplicações, nos meses de junho, agosto, outubro de 2011 e janeiro de 2012, para todos os tratamentos.
O critério de utilização da pastagem, durante o período hibernal, do estabelecimento ao final da utilização do azevém, teve como base a altura dessa forrageira $(20 \mathrm{~cm})$. No período estival, foi a altura do capim elefante, entre 100 e $120 \mathrm{~cm}$. A massa de forragem foi estimada com a técnica da dupla amostragem (WILM et al., 1944) com 20 estimativas visuais e 5 cortes, antes e depois do pastejos dos animais. Essa amostragem foi feita no alinhamento formado pelas touceiras de capim elefante e também na forragem presente nas entrelinhas. No capim elefante, os cortes foram realizados a $50 \mathrm{~cm}$ do solo e nas entrelinhas, rente ao solo. 
As amostras foram pesadas e homogeneizadas, foi retirada uma subamostra para estimativa das composições botânica da forragem e morfológica do capim elefante, posteriormente foram secas em estufa para determinação da matéria seca, e a seguir a massa de cada componente foi calculada.

A estimativa da massa de forragem foi feita em $26 \%$ da área total ocupada pelo capim elefante e $74 \%$ pelas espécies presentes entre as linhas formadas pelas touceiras do capim elefante.

Para determinar a carga animal instantânea, procurou-se manter a oferta de forragem de $4 \mathrm{~kg}$ de MS $100 \mathrm{~kg}^{-1}$ de peso corporal para a massa de lâminas foliares do capim elefante. Para a massa de forragem presente na entrelinha, estimou-se $8 \mathrm{~kg}$ de MS $100 \mathrm{~kg}^{-1}$ de peso corporal, durante todo o período experimental.

Vacas em lactação da raça Holandesa, com peso médio corporal de $554,5 \mathrm{~kg}( \pm 10,5, \mathrm{n}=12)$ e produção média de $19,9 \mathrm{~kg}$ de leite $\mathrm{dia}^{-1}( \pm 0,74, \mathrm{n}=12)$ foram utilizadas neste trabalho. Após as ordenhas as vacas receberam complementação alimentar correspondente a $0,9 \%$ do peso corporal. As vacas permaneceram nas pastagens das $9 \mathrm{~h}$ às $15 \mathrm{~h} 30 \mathrm{~min}$ e das $18 \mathrm{~h}$ às 6h30min.
O delineamento experimental utilizado foi o inteiramente casualizado com três tratamentos (sistemas forrageiros), duas repetições de área (piquetes) e em avaliações independentes (ciclos de pastejo). Os dados foram submetidos à análise de variância e as médias comparadas pelo teste de Tukey, ao nível de $10 \%$ de probabilidade do erro. As análises foram efetuadas com auxílio do pacote estatístico SAS (2001). O modelo estatístico referente à análise das variáveis estudadas dos sistemas forrageiros foi representado por: $Y_{i j k}=m+T_{i}+R_{j}\left(T_{i}\right)+C_{k}$ $+\varepsilon_{\mathrm{ijk}}$, em que $\mathrm{Y}_{\mathrm{ijk}}$ representa as variáveis dependentes; i o índice de tratamentos (sistemas forrageiros); $\mathrm{j}$ o índice de repetições (piquetes); $\mathrm{k}$ o índice de ciclos de pastejos; $\mathrm{m}$ é a média de todas as observações; $\mathrm{T}_{\mathrm{i}}$ é o efeito dos tratamentos; $\mathrm{R}_{\mathrm{j}}\left(\mathrm{T}_{\mathrm{i}}\right)$ é o efeito de repetição dentro dos tratamentos, $\mathrm{C}_{\mathrm{k}}$ é o efeito dos ciclos de pastejo e $\varepsilon_{i j k}$ é o erro experimental residual.

\section{RESULTADOS E DISCUSSÃO}

Foram realizados oito ciclos de pastejo nos sistemas forrageiros, que totalizou 339 dias. O tempo de ocupação variou de um a dois dias, o tempo médio de descanso foi de $33( \pm 6, n=3)$ e 40 dias $( \pm 5$, $\mathrm{n}=5$ ), nos períodos hibernal e estival, respectivamente. Para o ciclo médio 
verificado no período hibernal, há semelhança com as recomendações de Silva Neto et al. (2006) em estudo sobre o azevém através de técnicas de modelagem, compararam métodos de pastejo contínuo e rotacionado, em que ciclos de rotação de 30 dias (29 de descanso) implicam em maior consumo de forragem. O ciclo médio verificado no período estival é considerado longo, segundo as recomendações de Deresz (2001) onde períodos curtos de ocupação, de até três dias, e de descanso próximo a 30 dias para espécies de estação quente como o capim elefante, estão associados à melhor qualidade da forragem e ao desempenho animal. O resultado com ciclos mais longos no período estival deveu-se a estiagem ocorrida no verão.

Quanto à massa de forragem de prépastejo, houve similaridade entre os sistemas forrageiros (Tabela 1), exceção feita no primeiro pastejo, com maior valor para o consórcio com amendoim forrageiro. $\mathrm{O}$ valor médio de massa de forragem é considerado baixo, em parte devido ao déficit hídrico ocorrido no período estival. As médias dos sistemas foram inferiores ao verificado por Azevedo Júnior et al. (2012), de 3,5 $\mathrm{Mg} \mathrm{ha}^{-1}$, ao avaliar sistemas similares, porém, com maior quantidade de fertilizante nitrogenado.
Para a massa de forragem do capim elefante, verificou-se melhor desempenho no consórcio com trevo vermelho no pastejo realizado em janeiro. Parte desse resultado pode ser confirmado pela maior participação de lâminas foliares do capim elefante no pastejo efetuado em novembro, bem como de colmo, na avaliação feita em abril. Para a fração material senescente do capim elefante, os valores são baixos devido à época, o critério de amostragem feito a 50 $\mathrm{cm}$ do solo, às características da planta de hábito cespitoso e pela forma com que o capim foi estabelecido, permitiu-se que os animais se desloquem entre os alinhamentos formados pelas touceiras.

Quanto à massa de forragem presente entre os alinhamentos formados pelas touceiras de capim elefante (Tabela 1), houve diferença nos pastejos efetuados em julho e dezembro. No primeiro, o maior valor do consórcio com amendoim forrageiro deve-se, possivelmente, à contribuição dessa leguminosa à gramínea acompanhante, que se encontra estabelecida há vários anos nessa área e, no período hibernal, parte dessa estrutura é degradada e libera nutrientes, especialmente o nitrogênio (CARVALHO \& PIRES, 2008). 
Tabela 1. Massa de forragem de pré-pastejo dos componentes botânicos e estruturais (kg de matéria seca ha ${ }^{-1}$ ) de três sistemas forrageiros (SF).

\begin{tabular}{|c|c|c|c|c|c|c|c|c|c|c|}
\hline \multirow[b]{3}{*}{ SF } & \multicolumn{8}{|c|}{ Pastejos } & \multirow{3}{*}{$\begin{array}{c}\text { Média } \pm \text { Erro } \\
\text { padrão }\end{array}$} & \multirow{3}{*}{$\begin{array}{l}\mathrm{CV} \\
(\%)\end{array}$} \\
\hline & $1^{\circ}$ & $2^{\circ}$ & $3^{\circ}$ & $4^{\circ}$ & $5^{\circ}$ & $6^{\circ}$ & $7^{\circ}$ & $8^{\circ}$ & & \\
\hline & $\mathrm{Jul} / 11$ & Ago/11 & Set/11 & Nov/11 & Dez/12 & Jan/12 & Mar/12 & Abri/12 & & \\
\hline \multicolumn{11}{|c|}{ Massa de forragem do pasto } \\
\hline $\mathrm{SL}^{1}$ & $1090 \mathrm{~b}$ & 1700 & 1904 & 3143 & 2840 & 1944 & 2602 & 2930 & $2269 \pm 253,21$ & \multirow{3}{*}{4,37} \\
\hline $\mathrm{AM}^{2}$ & $1232 a$ & 2141 & 1990 & 2957 & 2699 & 1836 & 3328 & 2875 & $2382 \pm 246,04$ & \\
\hline $\mathrm{TV}^{3}$ & $1125 b$ & 2039 & 2375 & 3003 & 2507 & 2104 & 3217 & 3036 & $2426 \pm 242,23$ & \\
\hline \multicolumn{11}{|c|}{ Massa de forragem de capim elefante } \\
\hline SL & - & - & - & 390 & 279 & $507 \mathrm{ab}$ & 696 & 565 & $487 \pm 64,14$ & \multirow{3}{*}{9,18} \\
\hline $\mathrm{AM}$ & - & - & - & 322 & 274 & $406 \mathrm{~b}$ & 680 & 590 & $454 \pm 69,77$ & \\
\hline TV & - & - & - & 361 & 368 & $538 \mathrm{a}$ & 849 & 669 & $557 \pm 83,02$ & \\
\hline \multicolumn{11}{|c|}{ Lâmina foliar de capim elefante } \\
\hline SL & - & - & - & $113 b$ & 246 & 425 & 494 & 356 & $327 \pm 67,34$ & \multirow{3}{*}{10,88} \\
\hline $\mathrm{AM}$ & - & - & - & $209 \mathrm{ab}$ & 236 & 268 & 418 & 333 & $293 \pm 37,52$ & \\
\hline TV & - & - & - & $213 \mathrm{a}$ & 271 & 279 & 534 & 344 & $328 \pm 55,38$ & \\
\hline \multicolumn{11}{|c|}{ Colmo + bainha de capim elefante } \\
\hline SL & - & - & - & $207 \mathrm{a}$ & 29 & 67 & 192 & $161 b$ & $131 \pm 35,28$ & \multirow{3}{*}{22,91} \\
\hline $\mathrm{AM}$ & - & - & - & $26 b$ & 13 & 117 & 257 & $217 \mathrm{ab}$ & $126 \pm 49,14$ & \\
\hline $\mathrm{TV}$ & - & - & - & $30 \mathrm{~b}$ & 47 & 54 & 270 & $311 \mathrm{a}$ & $142 \pm 60,93$ & \\
\hline \multicolumn{11}{|c|}{ Material senescente de capim elefante } \\
\hline SL & - & - & - & 70 & $4 c$ & $15 \mathrm{~b}$ & $10 \mathrm{ab}$ & 48 & $29 \pm 12,69$ & \multirow{3}{*}{24,95} \\
\hline $\mathrm{AM}$ & - & - & - & 87 & $25 b$ & $21 b$ & $5 b$ & 40 & $36 \pm 14,01$ & \\
\hline TV & - & - & - & 118 & $50 \mathrm{a}$ & $205 \mathrm{a}$ & $45 \mathrm{a}$ & 14 & $86 \pm 34,17$ & \\
\hline \multicolumn{11}{|c|}{ Massa de forragem presente na entrelinha } \\
\hline SL & $1090 \mathrm{~b}$ & 1700 & 1904 & 2753 & $2561 \mathrm{a}$ & 1437 & 1906 & 2365 & $1965 \pm 200,80$ & \multirow{3}{*}{4,23} \\
\hline $\mathrm{AM}$ & $1232 \mathrm{a}$ & 2141 & 1990 & 2625 & $2425 b$ & 1430 & 2648 & 2285 & $2097 \pm 185,73$ & \\
\hline TV & $1125 b$ & 2039 & 2375 & 2642 & $2139 c$ & 1566 & 2368 & 2367 & $2078 \pm 176,75$ & \\
\hline \multicolumn{11}{|c|}{ Azevém } \\
\hline SL & 544 & 1330 & 1344 & 2157 & - & - & - & - & $1344 \pm 329,29$ & \multirow{3}{*}{6,84} \\
\hline $\mathrm{AM}$ & 745 & 1831 & 1434 & 1801 & - & - & - & - & $1453 \pm 252,59$ & \\
\hline TV & 768 & 1660 & 1950 & 1715 & - & - & - & - & $1523 \pm 259,48$ & \\
\hline \multicolumn{11}{|c|}{ Espécies de crescimento espontâneo } \\
\hline SL & 86 & 195 & 142 & 222 & $935 \mathrm{a}$ & $858 \mathrm{ab}$ & $1632 b$ & $2180 \mathrm{a}$ & $781 \pm 275,75$ & \multirow{3}{*}{20,99} \\
\hline $\mathrm{AM}$ & 63 & 122 & 89 & 212 & $255 \mathrm{~b}$ & $224 b$ & $785 c$ & $911 \mathrm{c}$ & $333 \pm 115,57$ & \\
\hline TV & 61 & 138 & 70 & 287 & $370 a b$ & $1190 \mathrm{a}$ & $2103 a$ & $1594 b$ & $727 \pm 280,39$ & \\
\hline \multicolumn{11}{|c|}{ Leguminosas } \\
\hline $\mathrm{AM}$ & - & - & 137 & $451 b$ & $883 a$ & $731 \mathrm{a}$ & $1483 a$ & $1222 \mathrm{a}$ & $818 \pm 201,30$ & \multirow{2}{*}{21,33} \\
\hline TV & - & - & - & $516 \mathrm{a}$ & $35 b$ & $143 b$ & $35 \mathrm{~b}$ & $416 b$ & $229 \pm 100,00$ & \\
\hline & & & & Material & morto pre & sente na & ntrelinha & & & \\
\hline SL & 460 & 175 & 418 & 374 & 1626 & 579 & 274 & 185 & $511 \pm 166,54$ & \\
\hline $\mathrm{AM}$ & 424 & 188 & 330 & 161 & 1287 & 475 & 380 & 152 & $425 \pm 130,73$ & 13,52 \\
\hline TV & 296 & 241 & 355 & 124 & 1734 & 233 & 230 & 357 & $446 \pm 185,90$ & \\
\hline $\begin{array}{l}{ }^{1} \mathrm{SL}= \\
{ }^{2} \mathrm{AM}= \\
\text { verme } \\
\text { coluna } \\
\text { ausênc } \\
\text { de vari }\end{array}$ & $\begin{array}{l}\mathrm{m} \text { leg } \\
\text { nsórci } \\
\text {, CE } \\
\text { liferen } \\
\text { do co } \\
\text { ão. }\end{array}$ & nosa, & $\mathrm{m}$ ele & e $(\mathrm{CE})$ & azevér & (AZE) & espécie & cresc & $\begin{array}{l}\text { nto espontâneo } \\
\mathrm{V}=\text { consórcio co } \\
\text { s por letras dist } \\
\mathrm{CE}+\text { trevo verı }\end{array}$ & $\begin{array}{l}\text { (ECE); } \\
\text { n trevo } \\
\text { atas, na } \\
\text { elho; - } \\
\text { ficiente }\end{array}$ \\
\hline
\end{tabular}


No segundo, o menor valor em ambos os consórcios deve-se à ação das leguminosas em controlar espécies de crescimento espontâneo (DIEHL et al., 2013). Esse resultado é evidenciado no consórcio com amendoim forrageiro devido à maior contribuição e participação mais uniforme dessa leguminosa nos pastejos efetuados entre novembro e abril.

Observa-se que a participação de espécies de crescimento espontâneo, constituídas especialmente por Paspalum spp., Cynodon spp., guanxuma (Sida santaremnensis) e cabelo-de-porco (Piptochaetium montevidense) é elevada no sistema sem leguminosa. No consórcio com trevo vermelho, a baixa participação dessa leguminosa a partir de dezembro, implicou em maior contribuição das espécies de crescimento espontâneo.

Com relação à participação das leguminosas, observa-se que o amendoim forrageiro esteve presente em seis dos oito ciclos de pastejo conduzidos, com média de $31,3 \%( \pm 6,38 ; n=6)$ da massa de forragem da pastagem e $36,6 \%( \pm 8,43 ; n=6)$ na massa de forragem presente nas entrelinhas. Esses valores estão próximos da recomendação de THOMAS (1992), de 30\%, considerada adequada à sustentabilidade do sistema forrageiro. Já para o trevo vermelho, presente em cinco ciclos de pastejo, destacase a baixa participação nos pastejos efetuados em dezembro e março, devido ao déficit hídrico ocorrido durante o verão. $\mathrm{O}$ valor médio do trevo vermelho na massa de forragem presente na entrelinha foi de $10,33 \%( \pm 3,82 ; n=5)$, que está abaixo da recomendação feita por CADISH et al. (1994), de 13 a $23 \%$ para pastagens consorciadas.

Para a massa de forragem de póspastejo (Tabela 2), os valores guardam similaridade com os de disponibilidade inicial. Ocorreram diferenças pontuais em alguns pastejos, possivelmente associadas à diversidade das touceiras de capim elefante. Em relação ao valor médio de lâminas foliares, o resíduo foi corresponde a 27,60\% $( \pm 1,14 ; \quad n=3), \quad$ considerado adequado à recuperação das plantas, de $25 \%$ (HILLESHEIM \& CORSI, 1990).

Os valores de massa de forragem residual (Tabela 2) apontam que houve diferentes taxas de desaparecimento de forragem dos componentes da pastagem, que indica a preferência dos animais pelas forrageiras que constituíram os sistemas foi distinta. Assim, para a média dos sistemas da massa de forragem do capim elefante, a taxa 
Tabela 2. Massa de forragem de pós-pastejo dos componentes botânicos e estruturais (kg de matéria seca ha ${ }^{-1}$ ) de três sistemas forrageiros (SF).

\begin{tabular}{|c|c|c|c|c|c|c|c|c|c|c|}
\hline \multicolumn{11}{|c|}{ Pastejos } \\
\hline & $1^{\circ}$ & $2^{\circ}$ & $3^{\circ}$ & $4^{\circ}$ & $5^{\circ}$ & $6^{\circ}$ & $7^{\circ}$ & $8^{\circ}$ & Média \pm Erro & $\mathrm{CV}$ \\
\hline SF & $\mathrm{Jul} / 11$ & Ago/11 & Set/11 & Nov/11 & Dez/12 & Jan/12 & Mar/12 & Abri/12 & padrão & $(\%)$ \\
\hline \multicolumn{11}{|c|}{ Massa de forragem do pasto } \\
\hline $\mathrm{SL}^{1}$ & 1099 & 884 & 814 & 2319 & $1674 \mathrm{a}$ & 928 & 2000 & 1794 & $1439 \pm 204,67$ & \multirow{3}{*}{5,25} \\
\hline $\mathrm{AM}^{2}$ & 936 & 914 & 780 & 2423 & $1319 b$ & 1503 & 1840 & 1777 & $1435 \pm 199,86$ & \\
\hline $\mathrm{TV}^{3}$ & 1054 & 842 & 861 & 2346 & $1221 b$ & 2380 & 2380 & 1696 & $1443 \pm 221,52$ & \\
\hline \multicolumn{11}{|c|}{ Massa de forragem de capim elefante } \\
\hline SL & - & - & - & 301 & $97 b$ & 342 & $292 b$ & 286 & $264 \pm 19,13$ & \multirow{3}{*}{7,31} \\
\hline $\mathrm{AM}$ & - & - & - & 341 & $225 \mathrm{a}$ & 273 & $299 b$ & 257 & $279 \pm 8,76$ & \\
\hline TV & - & - & - & 288 & $239 a$ & 369 & $401 \mathrm{a}$ & 267 & $313 \pm 13,82$ & \\
\hline \multicolumn{11}{|c|}{ Lâmina foliar de capim elefante } \\
\hline SL & - & - & - & $71 b$ & $40 \mathrm{~b}$ & 103 & 88 & 61 & $73 \pm 9,72$ & \multirow{3}{*}{11,25} \\
\hline $\mathrm{AM}$ & - & - & - & $102 \mathrm{a}$ & $89 a$ & 109 & 52 & 61 & $83 \pm 10,03$ & \\
\hline $\mathrm{TV}$ & - & - & - & $63 b$ & $64 \mathrm{ab}$ & 103 & 108 & 63 & $80 \pm 9,27$ & \\
\hline \multicolumn{11}{|c|}{ Colmo + bainha de capim elefante } \\
\hline SL & - & - & - & $176 a$ & 25 & 164 & 178 & 172 & $143 \pm 26,47$ & \multirow{3}{*}{19,03} \\
\hline $\mathrm{AM}$ & - & - & - & $122 \mathrm{ab}$ & 59 & 74 & 217 & 152 & $125 \pm 25,42$ & \\
\hline TV & - & - & - & $56 \mathrm{~b}$ & 58 & 164 & 264 & 170 & $142 \pm 34,99$ & \\
\hline \multicolumn{11}{|c|}{ Material senescente de capim elefante } \\
\hline SL & - & - & - & $54 \mathrm{c}$ & 32 & $75^{\prime}$ & 26 & 53 & $48 \pm 7,82$ & \multirow{3}{*}{16,35} \\
\hline $\mathrm{AM}$ & - & - & - & $117 \mathrm{~b}$ & 77 & 90 & 30 & 44 & $72 \pm 14,03$ & \\
\hline TV & - & - & - & $169 \mathrm{a}$ & 117 & 102 & 29 & 34 & $90 \pm 23,64$ & \\
\hline \multicolumn{11}{|c|}{ Massa de forragem presente na entrelinha } \\
\hline SL & 894 & 887 & 814 & 2018 & $1577 \mathrm{a}$ & 481 & 1708 & 1508 & $1274 \pm 177,09$ & \multirow{3}{*}{5,27} \\
\hline $\mathrm{AM}$ & 948 & 825 & 780 & 2082 & $1094 b$ & 960 & 1541 & 1520 & $1261 \pm 153,16$ & \\
\hline TV & 899 & 861 & 861 & 2058 & $982 b$ & 545 & 1979 & 1429 & $1247 \pm 182,78$ & \\
\hline \multicolumn{11}{|c|}{ Azevém } \\
\hline SL & 680 & 438 & 402 & 1333 & - & - & - & - & $713 \pm 215,61$ & \multirow{3}{*}{10,71} \\
\hline $\mathrm{AM}$ & 357 & 578 & 455 & 1415 & - & - & - & - & $701 \pm 242,17$ & \\
\hline $\mathrm{TV}$ & 721 & 613 & 632 & 1209 & - & - & - & - & $794 \pm 140,40$ & \\
\hline \multicolumn{11}{|c|}{ Espécies de crescimento espontâneo } \\
\hline SL & 164 & 104 & 95 & 455 & $93 b$ & 180 & $1006 a b$ & 1058 & $394 \pm 145,28$ & \multirow{3}{*}{19,99} \\
\hline $\mathrm{AM}$ & 350 & 106 & 99 & 245 & $10 \mathrm{c}$ & 314 & $475 b$ & 823 & $303 \pm 91,80$ & \\
\hline TV & 100 & 41 & 41 & 380 & $383 a$ & 407 & $1339 a$ & 869 & $445 \pm 160,02$ & \\
\hline \multicolumn{11}{|c|}{ Leguminosas } \\
\hline $\mathrm{AM}$ & - & - & 12 & $226 a$ & $345 \mathrm{a}$ & $628 \mathrm{a}$ & $472 \mathrm{a}$ & $270 \mathrm{a}$ & $326 \pm 86,53$ & \multirow{2}{*}{23,10} \\
\hline TV & - & - & - & $91 \mathrm{~b}$ & $46 \mathrm{~b}$ & $36 \mathrm{~b}$ & $9 b$ & $104 b$ & $57 \pm 17,65$ & \\
\hline \multicolumn{11}{|c|}{ Material morto presente na entrelinha } \\
\hline SL & 255 & 342 & 317 & 230 & 1484 & 406 & 702 & 450 & $523 a \pm 146,84$ & \multirow{3}{*}{18,67} \\
\hline $\mathrm{AM}$ & 217 & 230 & 214 & 196 & 739 & 288 & 594 & 427 & $363 b \pm 72,40$ & \\
\hline TV & 233 & 188 & 188 & 378 & 553 & 331 & 631 & 456 & $370 \mathrm{~b} \pm 59,10$ & \\
\hline
\end{tabular}


foi de $42,9 \%( \pm 2,18 ; n=3)$ e para o azevém, a taxa foi de $48,9 \%( \pm 1,51 ; n=3)$. Para as espécies de crescimento espontâneo, foi de $37,9 \%( \pm 12,12 ; n=3)$, que indica menor utilização em relação às demais; já as taxas de desaparecimento de forragem do amendoim forrageiro e do trevo vermelho, foram de $60,1( \pm 10,91 ; n=6)$ e $75,1 \%( \pm 1,72$; $\mathrm{n}=5$ ), que confirma melhor preferência pela leguminosa de ciclo hibernal (RUTTER, 2006).

Para as taxas de desaparecimento de forragem do pasto (Tabela 3), houve diferença entre os sistemas. O valor médio foi de 43,44\% $( \pm 1,92, n=3)$, que não implica em limitações de consumo, o que normalmente ocorre em taxas superiores a
$50 \%$ (DELAGARDE et al., 2001). O resultado obtido está associado à presença de forrageiras de ciclo estival, como o capim elefante e espécies de crescimento espontâneo, que apresentam taxas menores em função do menor valor nutritivo se comparadas com forrageiras de ciclo hibernal (STEINWANDTER et al., 2009).

Quanto à taxa de acúmulo de forragem (Tabela 3), os valores são baixos se comparados com sistemas forrageiros similares avaliados na mesma região, de 52 $\mathrm{kg}$ de MS ha- dia $^{-1}$ (DIEHL et al., 2013; AZEVEDO JUNIOR et al., 2012). Esse resultado deve-se, em parte, ao déficit hídrico ocorrido no período estival.

Tabela 3. Produtividade e taxa de lotação (médias \pm erro padrão) de três sistemas forrageiros (SF).

\begin{tabular}{|c|c|c|c|c|}
\hline \multirow{2}{*}{ Variável } & \multicolumn{3}{|c|}{$\mathrm{SF}$} & \multirow{2}{*}{$\begin{array}{l}\mathrm{CV} \\
(\%)\end{array}$} \\
\hline & $\mathrm{SL}^{1}$ & $\mathrm{AM}^{2}$ & $\mathrm{TV}^{3}$ & \\
\hline $\begin{array}{l}\text { Taxa de desaparecimento de } \\
\text { forragem }(\%)\end{array}$ & $39,97 \mathrm{~b} \pm 5,17$ & $43,76 a \pm 5,73$ & $46,59 a \pm 6,68$ & 1,07 \\
\hline $\begin{array}{l}\text { Taxa de acúmulo diário de forragem } \\
\left(\mathrm{kg} \text { de } \mathrm{MS} \mathrm{ha}{ }^{-1}\right)\end{array}$ & $32,60 \mathrm{~b} \pm 5,72$ & $33,87 \mathrm{ab} \pm 6,22$ & $35,18 \mathrm{a} \pm 8,12$ & 11,08 \\
\hline $\begin{array}{l}\text { Produção de forragem total (kg de } \\
\left.\mathrm{MS} \mathrm{ha}^{-1}\right)\end{array}$ & $9190 b \pm 228,89$ & $9590 \mathrm{a} \pm 237,44$ & $9788 \mathrm{a} \pm 261,70$ & 11,76 \\
\hline Taxa de lotação (UA ha $\left.{ }^{-1}\right)$ & $2,20 b \pm 0,28$ & $2,47 a \pm 0,38$ & $2,30 \mathrm{ab} \pm 0,32$ & 16,43 \\
\hline
\end{tabular}


Para a produção de forragem, houve diferença entre os sistemas com maior valor para os consórcios. Em trabalhos conduzidos com sistemas forrageiros similares, foram obtidos valores entre 14,6 (DIEHL et al., 2013) e $17,8 \mathrm{~kg}$ de MS ha-1 (AZEVEDO JUNIOR et al., 2012).

Para a taxa de lotação houve similaridade entre os consórcios, que demonstra superioridade do sistema com amendoim forrageiro sobre a pastagem sem leguminosa. Entre o consórcio com trevo vermelho e a pastagem constituída somente com gramíneas não houve diferença. Esse resultado deve-se, provavelmente, à baixa participação dessa leguminosa no sistema. Taxas de lotação similares foram obtidas por OLIVO et al. (2009), que consorciaram capim elefante com amendoim forrageiro ou trevo branco.

\section{CONCLUSÕES}

Os consórcios forrageiros que envolvem capim elefante, azevém, espécies de crescimento espontâneo, amendoim forrageiro ou trevo vermelho são viáveis, apresentam produtividade superior ao sistema sem leguminosa.

\section{REFERÊNCIAS BIBLIOGRÁFICAS}

AZEVEDO JUNIOR, R. L.; OLIVO, C. J.; MEINERZ, G. R.; AGNOLIM, C. A.; DIEHL, M. S.; MORO, G.; PARRA, . L.C.; QUATRIN, M. P.; HORST, T. 2012. Produtividade de sistemas forrageiros consorciados com amendoim forrageiro ou trevo vermelho. Ciência Rural, Santa Maria, v.42, n.11, p.20432050.

BRESOlIN, A. P. S.; CASTRO, C. M.; HERTER, F. G.; OLIVEIRA, A. C.; CARVALHO, F. I. F.; PEREIRA, F. B.; VIEIRA, C. L.; BERTOLI, R. F. 2008. Tolerância ao frio do amendoim forrageiro. Ciência Rural, Santa Maria, v.38, n.4, p.1154-1157, 2008.

CADISH, G.; SCHUNKE, R. M.; GILLER, K. E. 1994. Nitrogen cycling in a pure grass pasture and a grass-legume misture on a red latosol in Brazil. Tropical Grasslands, Brisbane, v.28, n.1, p. 4352.

CARVAlHO, G. G. P. \& PIRES, A. J. V. 2008. Leguminosas tropicais herbáceas em associação com pastagens. Archivos de Zootecnia, Córdoba, v.57, p.103-113.

CASTILHO, A. R. 2001. Potencial produtivo de ecotipos de Arachispintoi em el Piedemonte de los Llanos Orientales de Colombia. 
PasturasTropicales, Cali, v.23, n.1, p.19-24.

DELAGARDE, R.; PRACHE, S.; D'HOUR, P.; PETIT, M. 2001.Ingestion de l'herbe par les ruminants au pâturage. Fourrages, Versailles, v.166, n.1, p.189212.

DERESZ, F. 2001. Produção de leite de vacas mestiças holandês $\mathrm{x}$ zebu em pastagem de capim elefante manejadas em sistema de pastejo rotativo com e sem suplementação durante a época das chuvas. Revista Brasileira de Zootecnia, Viçosa, v.30, n.1, p.197-204.

DIEHL, M. S.; OLIVO, C. J.; AGNOLIN, C. A.; BRATZ, V. F.; DE BEM, C. M.; AGUIRRE, P. F.; GLIENKE, C. L.; CORREA, M. R.; SERAFIM, G. 2013. Produtividade de sistemas forrageiros consorciados com leguminosas. Arquivo Brasileiro de Medicina Veterinária e Zootecnia, Belo Horizonte, v.65, n.5, p.1527-1536.

EMPRESA BRASILEIRA DE PESQUISA EM AGROPECUÁRIA - EMBRAPA. Centro Nacional e Pesquisa em Solos. 2006. Sistema Brasileiro de Classificação de Solos. Brasília: Embrapa-SPI; Rio de Janeiro: EmbrapaSolos, $306 \mathrm{p}$.
HILLESHEIM, A. \& CORSI, M. 1990. Capim elefante sob pastejo. II-Fatores que afetam as perdas e utilização de matéria seca. Pesquisa Agropecuária Brasileira, Brasília, v.25, n.9, p.12331246.

LENZI, A.; CECATO, U.; MACHADO FILHO, L. C. P.; ANITA, M.; GASPARINO, E.; ROMA, C. F. C.; BARBERO, L. M. 2009. Dinâmica do nmineral em pastagem de Coastcross consorciado com Arachispintoi com ou sem nitrogênio em duas estações do ano. Revista Brasileira de Agroecologia, Cruz Alta, v.4, n.1, p.51-58.

OLIVO, C. J.; ZIECH, M. F.; BOTH, J. F.; MEINERZ, G. R.; TYSKA， D.; VENDRAME, T. 2009. Produção de forragem e carga animal em pastagens de capim-elefante consorciadas com azevém, espécies de crescimento espontâneo e trevo-branco ou amendoim forrageiros. Revista Brasileira de Zootecnia, Viçosa, v.38, n.1, p.27-33.

PAIM, N. R. \& RIBOLDI, J. 1994. Duas novas cultivares de trevo branco comparadas com outras disponíveis no Rio Grande do Sul, em associação com gramíneas. Pesquisa Agropecuária Brasileira, Brasília, v.29, n.1, p.43-53. 
RUTTER, S. M. 2006. Diet preference for grass and legumes in free-ranging domestic sheep and cattle: Current theory and future application. Applied Animal Behaviour Science, Amsterdam, v.97, p.17-35.

SANTOS, H. P.; FONTANELI, R. S.; BAIER, A. C. 2002. Principais forrageiras para integração lavourapecuária, sob plantio direto, nas Regiões Planalto e Missões do Rio Grande do Sul, Passo Fundo: Embrapa Trigo, $142 \mathrm{p}$.

SAS INSTITUTE, SAS. 2001. Statistical analysis user's guide. Version 8.2, Cary: SAS Institute, $1686 \mathrm{p}$.

STEINWANDTER， E.; OLIVO， C. J.; SANTOS, J. C.; ARAUJO, T. L. R.; AGUIRRE, P. F.; DIEHL, M. S. 2009. Produção de forragem em pastagens consorciadas com diferentes leguminosas sob pastejo rotacionado. Acta Scientiarum. Animal Sciences, Maringá, v.31, n.2, p.131-137.

SILVA NETO, B.; SCHNEIDER, M.; VIEGAS, J. 2006. Modelo de simulação de sistemas de pastejo rotativo e contínuo de azevém (Lolium multiflorum Lam.) na bovinocultura. Ciência Rural, Santa Maria, v.36, n.4, p.1272-1277.
SOBCZAK, M. F.; OLIVO, C. J.; GABBI, A. M.; CHARÃO, P. S.; HEIMERDINGER， A.; SOUZA DA SILVA， J. H.; PEREIRA， L. E. T.; ZIECH, M. F.; ROSSAROLLA, G. 2005. Evaluation of an elephantgrass pasture mixed with black oat managed under agroecological principles in winter period. Livestock Research for Rural

Development, Cali, v.17, n.6, p.1-3.

Recebido em: 12/12/2013 Aceito para publicação em: 18/08/2014 